Volume 10, Issue 4, July-August 2019, pp.36-43, Article ID: IJM_10_04_005

Available online at http://iaeme.com/Home/issue/IJM?Volume $=10 \&$ Issue $=4$

Journal Impact Factor (2019): 9.6780 (Calculated by GISI) www.jifactor.com

ISSN Print: 0976-6502 and ISSN Online: 0976-6510

\title{
IMPACT OF SECURITY AND PRIVACY ISSUES IN INTERNET MARKETING-A STUDY.
}

\author{
Koppisetti Durgabhavani \\ Research Scholar, Bharathiar University, Tamilnadu, India. \\ Dr. A. R Krishnan \\ Faculty of Management, SRM IST, Chennai, India.
}

\begin{abstract}
Purpose of the study is to analyze security issues which have an impact on the online shopping buying behavior of the customer. Also highlights the factors which helps in retaining the online customer. The survey is conducted with 175 consumers. A Questionnaire was designed with 5 points Likert scale (Strongly agree - 1 to strongly disagree - 5) and ranking. The article also focuses on the relationship and the significance between securities versus online purchasing. For effective analysis, statistical tools like factors analysis and correlation test are performed.
\end{abstract}

Keywords: Digital market - privacy - security - risk - risk reduction.

Cite this Article: Koppisetti Durgabhavani and Dr. A. R Krishnan, Impact of Security and Privacy Issues in Internet Marketing-a Study, International Journal of Management, 10 (4), 2019, pp. 36-43.

http://iaeme.com/Home/issue/IJM?Volume=10\&Issue $=4$

\section{INTRODUCTION}

The term privacy includes both ethical and legal aspects. Privacy was coined in twentieth century. The reason for the emergence of this term in online business is due to the increase in the usage and adoption of internet in public life as well as in developing businesses has led to a phenomenal rise in online shopping. Even though there is a increase in the population of online customers it always accompanied with a threat of personal information being shared and it seems to be one of the hindrance, which prevents customers from shopping online. This article mainly focuses on the security and the privacy related issues of the customer shopping online.

\section{LITERATURE REVIEW}

\subsection{Introduction to e - commerce}

Electronic business generally interpreted as e-business or internet business, it can also be defined $^{[1]}$ as a support to all activities carried in a business. E-business was initially coined by IBM's marketing and internet team in 1996. These methods are efficient and flexible in linking company's internal and external data processing systems. Also ensures a better working 
condition with suppliers and partners to meet the needs and expectation of the customers. ecommerce has become the iconic word of today's business world.

\section{A. Types of E-commerce:}

An organization with its trade partners organizes to conduct e-commerce businesses with the consumers. It can be any form of the business ranging from Business - to Business (B2B), Business - to - Consumer (B2C), Consumer - to - consumer (C2C).

\section{Table 1}

Types of e-commerce.

\begin{tabular}{|c|c|c|c|}
\hline Types & Government & Business & Consumer \\
\hline Government & $\begin{array}{c}\text { G2G } \\
\text { Example: Center } \\
\text { \& State }\end{array}$ & $\begin{array}{c}\text { G2B } \\
\text { e-tenders }\end{array}$ & $\begin{array}{c}\text { G2C } \\
\text { Information to } \\
\text { citizens, online forms }\end{array}$ \\
\hline Business & $\begin{array}{c}\mathrm{B} 2 \mathrm{G} \\
\text { Procurement }\end{array}$ & $\begin{array}{c}\mathrm{B} 2 \mathrm{~B} \\
\text { EDI, EFT }\end{array}$ & $\begin{array}{c}\mathrm{B} 2 \mathrm{C} \\
\text { Flipkart.com, } \\
\text { Amazon.com }\end{array}$ \\
\hline Consumer & $\begin{array}{c}\mathrm{C} 2 \mathrm{G} \\
\text { Online filling of } \\
\text { tax returns }\end{array}$ & $\begin{array}{c}\text { C2B } \\
\text { Job portals like } \\
\text { naukri.com, } \\
\text { monster.com }\end{array}$ & $\begin{array}{c}\mathrm{C} 2 \mathrm{C} \\
\text { Facebook.com, } \\
\text { ebay.com }\end{array}$ \\
\hline
\end{tabular}

\section{B. Online Privacy Problem:}

The concept of privacy revolves around information pertaining to marketing as well as electronic commerce. Which leads to the conflicts about the data usage and collected this discussion was initiated by the AMA code of Ethics for Marketing. They state that the information collected from the customers must not be misused and confidentiality must be maintained. The principle is precise and straight forward. Measures has to be taken to ensure that these principles are used in all information gathering resources.

The data are misused through cookies. Based on the user request from the web pages the data are stored in form of a packets, these are referred to as Cookies. It can be used later. The stored data which is in user computer will be transferred to the relevant web site. Many purposes are solved with the cookies. Example, they are used for gathering information, in shopping websites to hold previous transactions, reminder of upcoming products, offers, to inform about the items which are in transit or to suggest of alternative products. In addition to these cookies collect complete information regarding the customer address, email address, postal address, contact number IP address of their devices, geographic location of the customers and so on. Unethical practice of misusing the customer information can be done with these cookies. The data in these cookies can be transmitted to other device and can be used misused for any purpose.

Tracking of the users occurs when cookies are examined during a user's tenure in online. It results in identifying the online behavior of the consumer. With the integration of the off-line data, to find out whether there is a correlation between sites requesting for personal information and the percentage of information revealed by the customer. These forms of tracking results in identifying more troubling dimension. 


\section{Trust}

As per Moorman, Deshpande and Zaltman (1993, p82) "The willingness to rely on an exchange partner in whom one has confidence". Berry (1995) mentions, for a successful relationship trust must be maintained throughout. According to Geyskens and Steenkamp (1995), to obtain the cooperation from the customers, one has to main the trust with the partner.

Thus, to improvise the business the strength of the partners and the customer can be accomplished by trust. Ruyter et al. (2004) proved that through trust one can stay for a longer time and thus paves way for a positive business. Thus, strength plays a important role in business

\section{OBJECTIVES OF THE STUDY}

1. To identify the location in which the customers are connected to the internet.

2. To find out the correlation between the usage of interest and their purpose of surfing the internet.

3. To analyze the importance of the consent of the customer towards security factors.

4. To find out consumer overall satisfaction level towards security in websites.

\section{METHODOLOGY AND DATA COLLECTION}

\subsection{Sample size and Population determination}

Respondents who uses digital markets are the respondents for the study and they are limited to south Chennai. The study involves a non-probability convenient sample.

\subsection{Research instrument}

The study is conducted with a structured questionnaire and the questionnaire is completed with personal interviews. Questionnaire structure comprises of a closed-ended question. Five- point Likert-type statements are asked to respondents to identity their choices on the numerous digital marketing drive. Statistical method is used for the study.

\subsection{Data collection}

Data are collected through primary source and secondary source. Questionnaire were used to collect the primary source of data. Books, journals, academic papers are used to collect the secondary data.

\subsection{Analysis of data}

The data which is collected through questionnaire must undergo a series of analysis to ensure the efficiency and correctness of the collected data. As per the current study, analysis of data is carried out in 3 different phases. They are mentioned below;

Preliminary analysis: This study involves visual examination of the data which is collected through various resources. This analysis is carried out to ensure the reliability of the data.

Primary analysis: The researcher reviews he data to ensure that the collected data is sufficient to answer the objectives of the research.

Statistical Analysis: It is considered as the last phase of analysis. In this phase the data collected, reviewed are analyzed using statistical tools. In view of the goal and the information gathered the devices are utilized to break down the dependability of the information so gathered. In this examination SPSS (Statistical Package for Social Sciences). The factual programming bundle SPSS, Version 21 was utilized for examination. 


\subsection{Reliability and validity}

As per Yin (2009), any research is considered as reliable and vibrant to ensures the various measures to validate the data. Golafshani (2003), insist that based on the researcher and the research methods the reliability and validity of the research can be obtained. Golafshani (2003) Also specifies that the manner in in which the data gathered, collected, analyzed and interpreted also plays an vital role in the obtaining the reliability and validity of the research. Before the actual analysis is conducted a preliminary analysis were performed to the data collected. The results of this study can be relied.

\subsection{Ethical considerations}

As per Elliot (2005), researchers must emphasis on the ethical issues and ensure that they address various ethical issues. There are many ethical issues involved in the research. It ranges from collection of data from the respondent to preparation of analysis report to the customer. The data collected form the respondents are kept confidential and will not be disclosed with any one. These are measures are taken to maintain the code of ethics.

\section{DATA ANALYSIS AND RESULT}

The reliability of the data is tested using the Cronbach's Alpha test, the Value of the Cronbach's Alpha test is .787. The value of Cronbach's Alpha founded on Standardized items is .806 which is greater than 0.7, hence the internal consistency of the items is Acceptable.

Table 5.1

Reliability Statistics

\begin{tabular}{|l|l|l|}
\hline Cronbach's Alpha & $\begin{array}{l}\text { Cronbach's Alpha Based on } \\
\text { Standardized Items }\end{array}$ & N of Items \\
\hline 787 & .806 & 13 \\
\hline
\end{tabular}

To find out the location in which the customers are connecting to the internet.

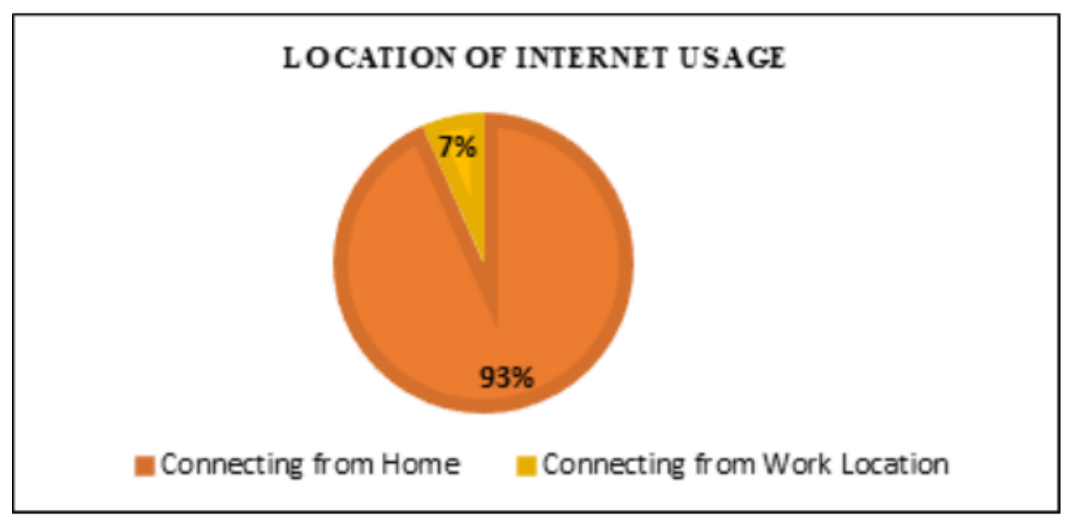

Figure. 5.1. Diagram of internet usage

As per the study the customers prefer to connect from home rather than their work location. They prefer to connect with their network than any other internet sources. If it's for some official purpose customers would prefer for connecting to a work location network else the frequency of connecting to other network is minimal. This ensures a customer feel comfortable and secured while connecting with their personal network connection. Which they feel it is more secured and safe. 


\subsection{To find the correlation between the usage of interest and their purpose of surfing internet.}

H0: Null Hypothesis: There is no significance difference between the usage of interest and their purpose of surfing internet.

H1: Alternative Hypothesis: There is a significance difference between the usage of interest and their purpose of surfing internet

Table 5. 2

Communalities

\begin{tabular}{|l|l|l|}
\hline & Initial & Extraction \\
\hline Entertainment Purpose & 1.000 & .955 \\
Education purpose & 1.000 & .939 \\
Work related & 1.000 & .894 \\
Financial Trading & 1.000 & .859 \\
Current Events & 1.000 & .729 \\
Travel related & 1.000 & .916 \\
Product info & 1.000 & .813 \\
Online Shopping & 1.000 & .930 \\
Communication with others & 1.000 & .935 \\
Utility bill payment & 1.000 & .854 \\
\hline
\end{tabular}

Extraction Method: Principal Component Analysis.

Initial communalities are appraisals of the change in every factor represented by all segments or factors. Extraction communities are evaluations of the change in every factor represented by the elements in the factor arrangement. Small values demonstrate factors that don't fit well with the factor arrangement and ought to potentially be dropped from the investigation. As we do not have any small values in the communalities Extraction. All the factors should be included for analysis.

Table 5.3

\begin{tabular}{|c|c|c|c|c|}
\hline \multicolumn{5}{|c|}{ Rotated Component Matrix } \\
\hline & \multicolumn{4}{|c|}{ Component } \\
\hline & 1 & 2 & 3 & 4 \\
\hline Financial Trading & .892 & -.057 & .242 & .038 \\
\hline Travel related & .854 & .158 & .215 & .340 \\
\hline Work related & .775 & .111 & -.530 & .014 \\
\hline Utility bill payment & .706 & .408 & .382 & .207 \\
\hline Entertainment Purpose & .107 & .931 & .232 & .152 \\
\hline Communication with others & .068 & .922 & -.128 & .253 \\
\hline Education purpose & -.303 & -.191 & -.875 & .213 \\
\hline Current Events & .080 & -.030 & .749 & .401 \\
\hline Online Shopping & .106 & .191 & .012 & .939 \\
\hline Product info & .292 & .454 & .112 & .713 \\
\hline \multicolumn{5}{|c|}{$\begin{array}{l}\text { Extraction Method: Principal Component Analysis. } \\
\text { Rotation Method: Varimax with Kaiser Normalization. }\end{array}$} \\
\hline Rotation converged in 5 iterati & & & & \\
\hline
\end{tabular}


Each number represents the correlation between the items. As all the items fall within the range of -1 to +1 .The alternative hypothesis is accepted and the null hypothesis is rejected. Thus, there is a significance difference between the usage of interest and their purpose of surfing internet.

\subsection{To analyze the importance of the consent of the customer towards security factors.}

From this study it shows, based on the necessity of the site (fig.2.) customer are willing to share $17 \%$ personal information, $16 \%$ has an neutral opinion on sharing data, $54 \%$ disagree and $13 \%$ strongly disagree on sharing personal data. If the online websites compensate for the data which is shared then, $47 \%$ customer are not willing to share i.e. they strongly disagree for the compensation, $33 \%$ disagree, $20 \%$ of the customer agree for the compensation.

When it comes to awareness (fig. 3) about the security and the information regarding safe usage of websites, $46 \%$ customers strongly disagree that awareness regarding the security measures was not advised to them, 18\% customers disagree, $34 \%$ has an neutral opinion on it and only $2 \%$ agree that security awareness regarding the safe use of internet was advised to them by the owners of the website.

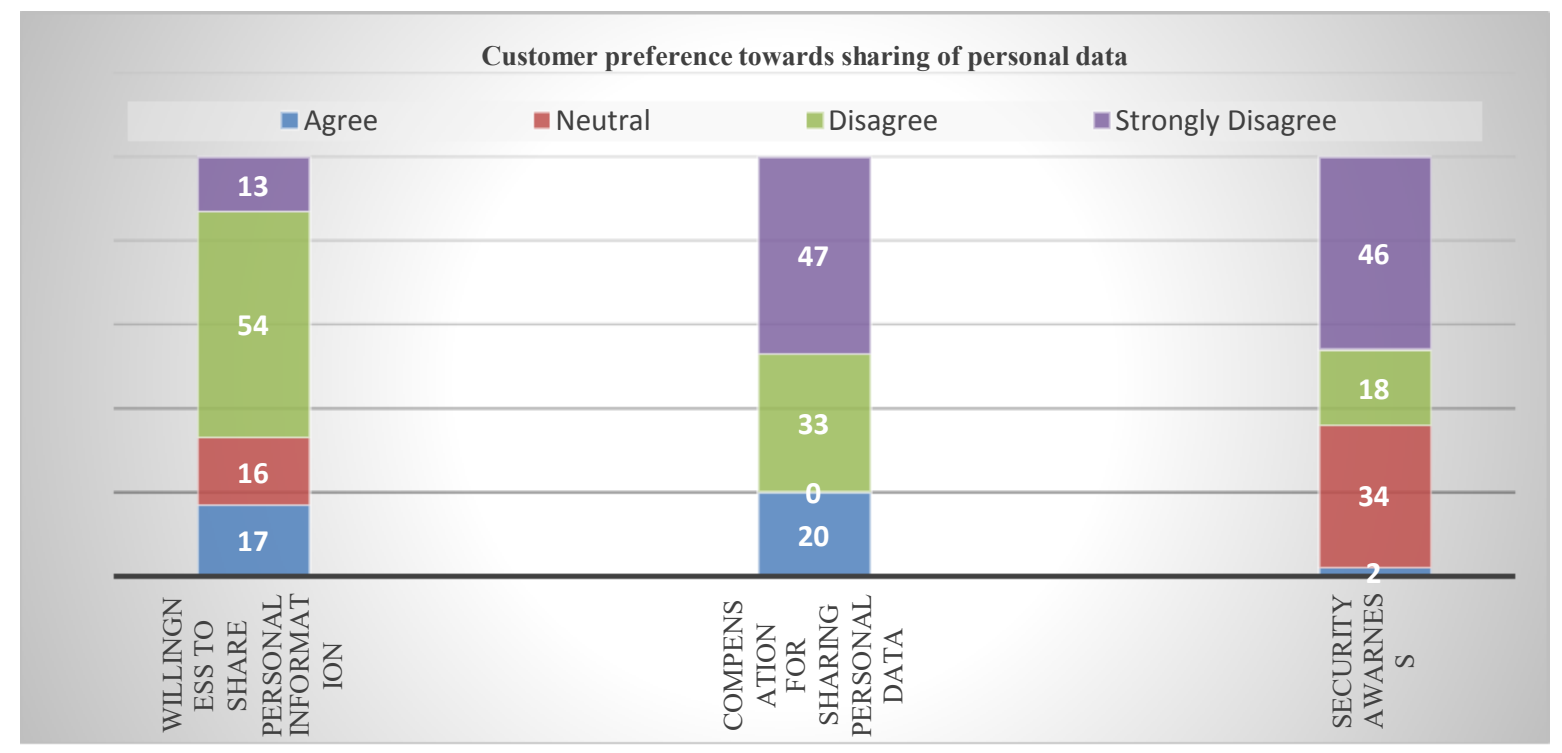

Figure. 2. Diagram on customer preference towards sharing of personal data 


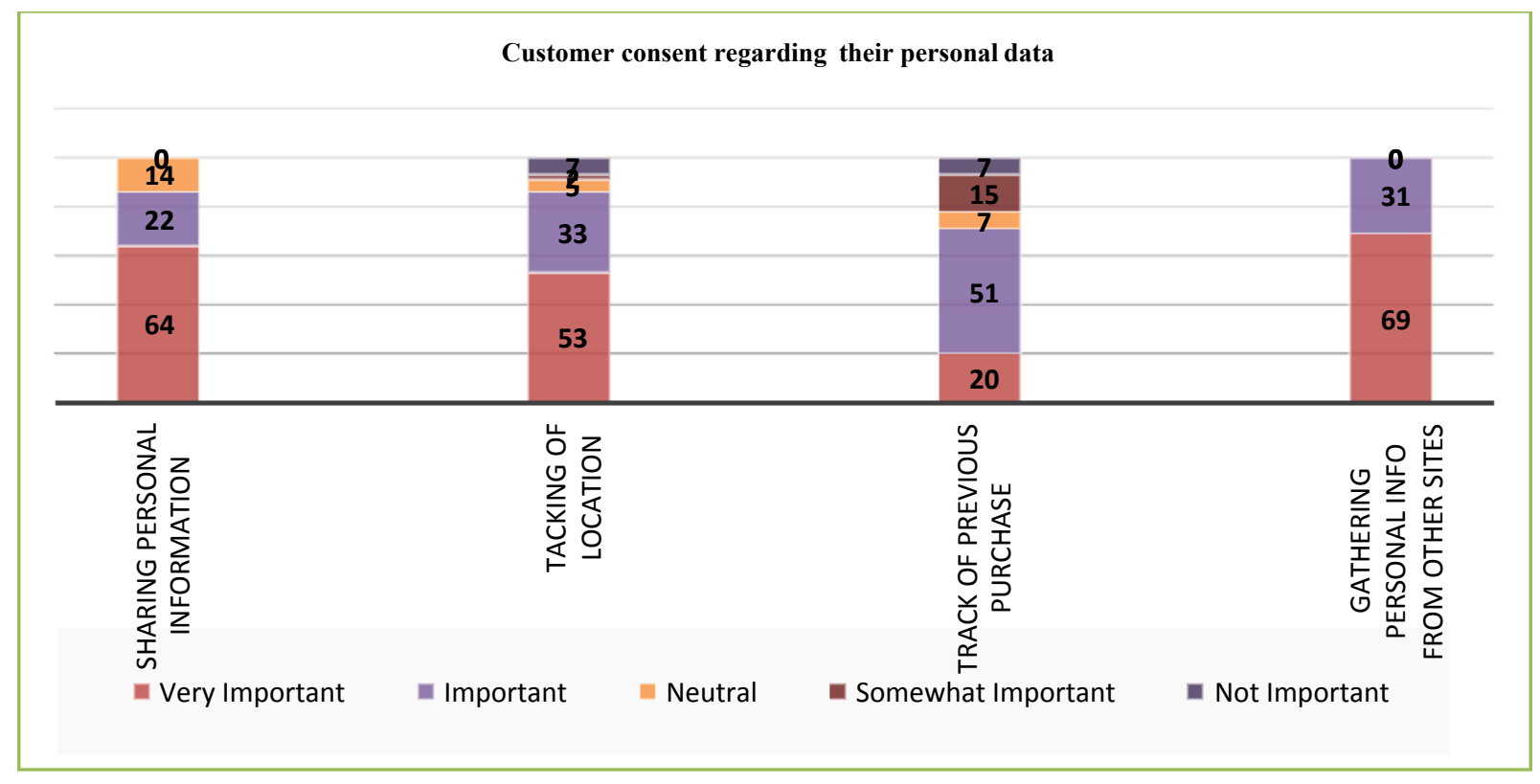

Figure.3. Customer consent regarding their personal data

The study shows that the consent of the customer is highly important for the data to share, track and to retrieve the data from other sites. For $64 \%$ of customers it is very important that their consent for sharing of personal information is required, $22 \%$ its important, $14 \%$ has a neutral opinion in express their consent towards willingness in sharing of personal information in websites. For 53\% of customer it's very important that their consent is required for tracking the customer location, 33\% it's important, 5\% neutral, 2\% somewhat important and 7\% not important. Customer consent regarding tracking of previous purchase shows that, $20 \%$ of customers feels it's very important to express their consent, for $51 \%$ it's important, $7 \%$ has a neutral opinion, $15 \%$ somewhat important and 7\% feels it is not important.

This study also reveals the consent of the customer if their personal data are gathered from other websites. $69 \%$ very important and their consent is required when information is gathered from other websites and $31 \%$ feels it is important that their consent is required, but none has a neutral opinion neither, somewhat important nor not important to express their consent.

\subsection{To find consumer overall satisfaction level towards security in websites.}

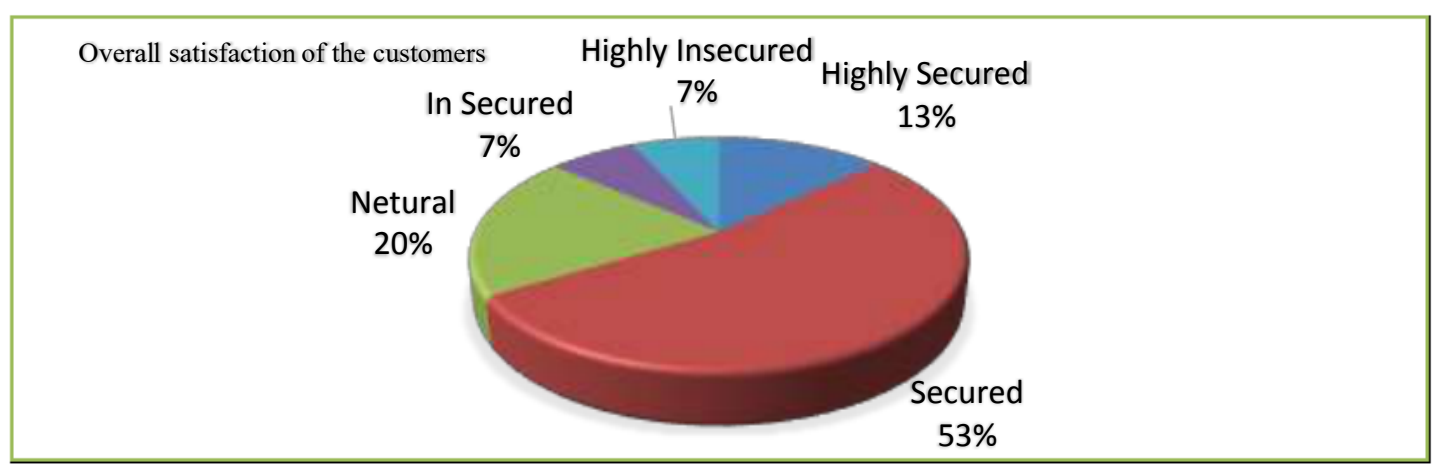

Figure.4. Overall satisfaction of the customers.

Despite various hardships and factors affecting the trust and worthiness of the web sites. $53 \%$ feel secured, $13 \%$ are highly secured, $20 \%$ has neutral opinion, $7 \%$ are in secured and $7 \%$ are highly in secured. 


\section{CONCLUSION AND RECOMMENDATIONS}

According to the study it is obvious that security towards personal information is more important, irrespective of the age, the reason for surfing the internet, the usage frequency and purpose. Even though there are few pitfalls customers prefer internet shopping.

It is recommended that the customers are educated about the awareness and safe usage of internet. As most of the transactions are carried through the internet the privacy of customer information must be maintained.

Without the consent of the customer information must not be shared. Strict privacy policies must be maintained. Violating of these policies should have some serious punishments only then customers information will be safe from being misused. The overall satisfaction of the customers who feel secured in using the online shopping is more, even though there are a few hindrances in using the internet, the overall percentage has a positive impact. Thus, measures must be taken to ensure that the unsecured feeling is increased by strengthening the security levels of the sites and more awareness must be given to educate the customers so that a safe and happy shopping is accomplished.

\section{REFERENCES:}

[1] Moorman, C., Zaltman, G., \&Deshpande, R, Relationship between Providers and users of marketing research: the dynamics of trust within and between organizations. Journal of marketing research, 29, 1992, pp 314-329.

[2] Berry, L. L, Relationship Marketing of Services Growing Interest, Emerging Perspectives. Journal of the Academy of Marketing Science, 23, 1995, pp 236-245.

[3] Murad Omarov, Tatyana Tikhaya and Vyacheslav Lyashenko, Internet Marketing Technologies In Civil Engineering, International Journal of Civil Engineering and Technology, 9(7), 2018, pp. $1233-1240$

[4] Geyskens, I., \& Steenkamp, J. E. M, An investigation into the joint effects of trust and interdependence on relationship commitment. In Bergadaa, M. (Ed.) Proceedings of the 24th Annual, 1995

[5] Chaffey, D., \& Smith, P, E marketing Excellence: planning and optimizing your digital marketing. Routledg, 2008

[6] Ami Dilham, Fivi Rahmatus Sofiyah and Iskandar Muda, The Internet Marketing Effect on the Customer Loyalty Level with Brand Awareness as Intervening Variables. International Journal of Civil Engineering and Technology, 9(9), 2018, pp. 681-695.

[7] Moorman, C.; Deshpande, R.; and Zaltman, G. Factors affecting trust in marketing research relationships. Journal of Marketing, 57 (January 1993), 81-101.

[8] Toñita Perea y Monsuwé, Benedict G.C. Dellaert, Ko de Ruyter,"What drives consumers to shop online? A literature review", International Journal of Service Industry Management, Vol. 15 Iss: 1, 2004, pp.102- 121 .

[9] Geyskens, I., \& Steenkamp, J. E. M.an investigation into the joint effects of trust and interdependence on relationship commitment. In Bergadaa, M. (Ed.) Proceedings of the 24th Annual Conference of the European Marketing Academy, ESSEC, Cergy-Pontoise, 1995, pp35171.

[10] Ruyter, K. D., Moorman, L., \& Lemmink, J, Antecedents of commitment and trust in customersupplier relationship in high technology markets. Industrial Marketing Management, 30, 2004, 271 